\title{
Myositis Ossificans of Masseter Muscle - A Rare Case Report
}

\section{N Aravindan', R Sathyanarayanan², Raghu K ${ }^{3}$, Raja Sethupathy Cheeman $^{4 *}$, Deepika Reddy $C^{5}$ and Rohan Singh Chadha ${ }^{1}$}

${ }^{1}$ Post-Graduate, Department of Oral and Maxillofacial Surgery, Indira Gandhi

Institute of Dental Sciences, Puducherry, India

${ }^{2}$ Professor and Head, Department of Oral and Maxillofacial Surgery, Indira Gandhi

Institute of Dental Sciences, Puducherry, India

${ }^{3}$ Reader, Department of Oral and Maxillofacial Surgery, Indira Gandhi Institute of

Dental Sciences, Puducherry, India

${ }^{4}$ Senior Lecturer, Department of Oral and Maxillofacial Surgery, Indira Gandhi

Institute of Dental Sciences, Puducherry, India

${ }^{5}$ Senior Resident, Department of Oral and Maxillofacial Surgery, Government

Dental College and Hospital, Hyderabad, India

*Corresponding Author: Raja Sethupathy Cheeman S, Assistant Professor, Senior Lecturer, Department of Oral and Maxillofacial Surgery, Indira Gandhi Institute of Dental Sciences, Puducherry, India.
Received: December 24, 2021

Published: January 07, 2022

(C) All rights are reserved by Raja Sethupathy Cheeman., et al.

\section{Abstract \\ Myositis ossificans traumatica (MOT) is a non-neoplastic, heterotopic bone growth within muscle or fascia that is thought to be caused by acute trauma, but it can also be caused by a variety of other factors. A 14 year-old boy presented with progressive limita- tion of mouth opening over the period of one month. Computed tomography revealed multiloculated cystic lesion seen overlying outer cortex ramus of left mandible and peripheral rim calcification at deeper fibers of left masseter muscle, and also thin solid peri- osteal reaction seen in adjacent to outer cortex of left ramus of mandible. Since 1924, only 52 occurrences of MOT of the masseter muscle have been described in the English literature. The major treatment option is surgical excision of the ossification, with ongoing postoperative monitoring to prevent relapse.}

Keywords: Myositis Ossificans; Bone; Cortex; Trauma

\section{Introduction}

Bone has a remarkable ability to grow, remodel, and regenerate. Orthotropic bone is formed within or in close proximity to the skeleton, while heterotopic bone is formed in tissues that do not ordinarily ossify [1]. Myositis ossificans (MO) is also known as Myositis ossificans traumatica (MOT) since it is linked to a single or repeated muscle injury in more than half of the cases. An osteoblast stimulation as a result of bone or soft tissue damage generating formation of new bone, dystrophic calcifications, or calcified chondroid matrix is the most widely accepted etiologic mechanism [2-4].

CAREY [5] proposed four main theories for its development: displacement of bony fragments into the soft tissue with subsequent proliferation; detachment of periosteal fragments into the surrounding tissue with proliferation of osteoprogenitor cells; migration of subperiosteal osteoprogenitor cells into surrounding soft tissue, through periosteal perforation induced by trauma; and metaplasia of extraosseous cells exposed to bone morphogenic 
proteins derived from the lysis of bone fragments displaced within the soft tissue during traumatic injury.

ARIMA., et al. [6] suggested that autolysis of scattered bone fragments produces bone morphogenic protein (BMP), which causes perivascular mesenchymal cells to differentiate into muscle tissue, resulting in a rather homogeneous bony mass. The time between trauma and the first diagnosis of a calcified mass ranged from 3 weeks to more than 20 years, according to the researchers.

The aim of this article is to report a case of a 14 year-old boy with MO located in the masseter muscle and a literature review about MO related to masticatory muscles.

\section{Case Report}

A 14 years-old boy had reported to the department of Oral and Maxillofacial Surgery with the chief complaint of pain, swelling, progressive growth in the left cheek region and difficulty in mouth opening for past 1 month (Figure 1). He gives medical history of herpes zoster infection 6 months back.

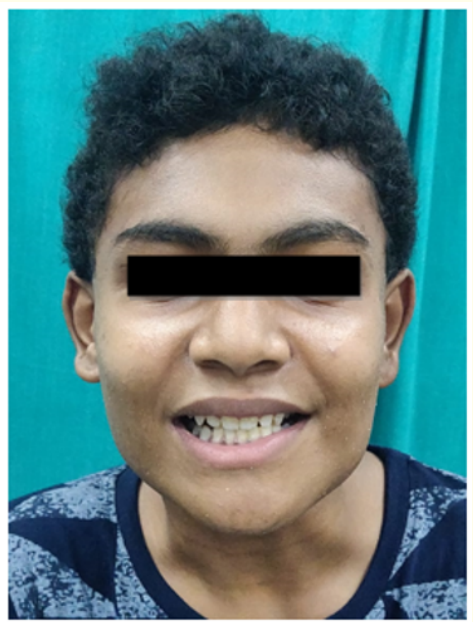

Figure 1

A Non Contrast CT scan were performed that shows multiloculated cystic lesion seen overlying outer cortex ramus of left mandible and peripheral rim calcification at deeper fibers of left masseter muscle (Figure 2), and also thin solid periosteal reaction seen in adjacent to outer cortex of left ramus of mandible. To define its histology an incisional biopsy of the lesion was done. The Histo- pathological study reflected morphologic changes compatibles with myositis ossificans. No malignant signs were observed in the specimen. Surgical removal of the lesion under general anaesthesia was done by a left submandibular approach (Figure 3a). The lesion was exposed after a careful dissection in order to preserve the marginal nerve and lesion was excised, with $1 \mathrm{~cm}$ of tumor-free margins. The underlying periosteum of masseter muscle was inflamed (Figure -3b) and it was removed as the outer cortical plate was not normal. Corticotomy done between 35 and 38 region and the surrounded muscle also excised (Figure 3c). The corticotomy site was plated in order to obtain the external contour of mandible (Figure 3d). The Histopathological analysis described a chronic inflammatory cell infiltrate of skeletal muscle with enchondral ossification of bone tissue compatible with myositis ossificans. At postoperative regular follow-up patient had no pain, with improvement in mouth opening of $42 \mathrm{~mm}$ with good lateral and protrusive movements. The authors also strongly believe that the secondary effect of postsurgical scarring should not be ignored and intensive physiotherapy should be part of postoperative care.
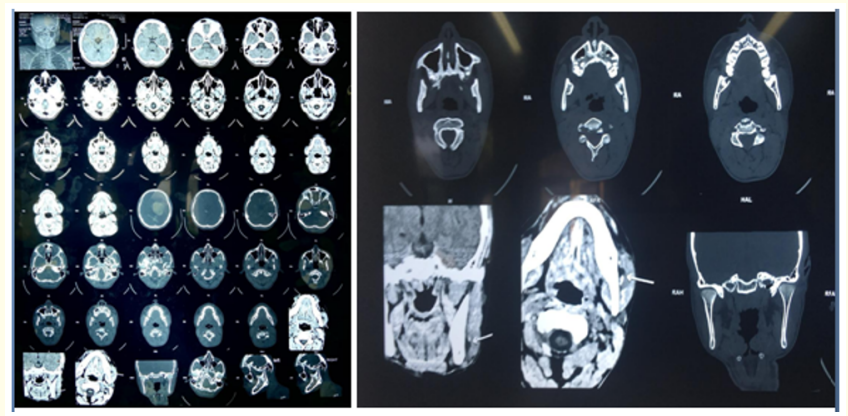

Figure 2
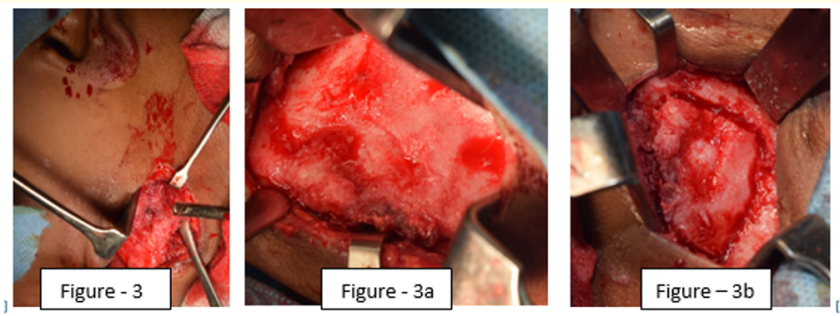

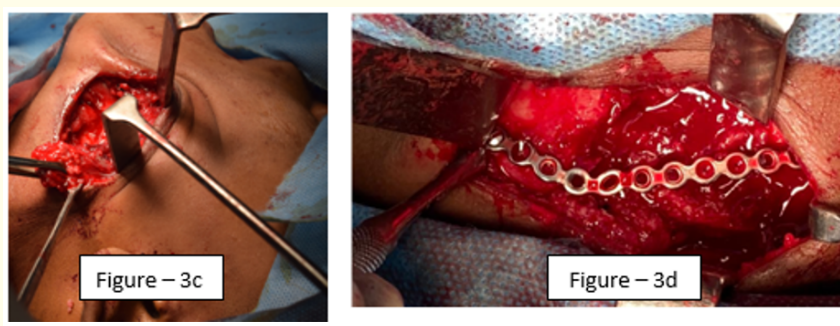

Figure 3: a - Excision of lesion through submandibular approach. b- Underlying periosteum of masseter muscle was inflamed.
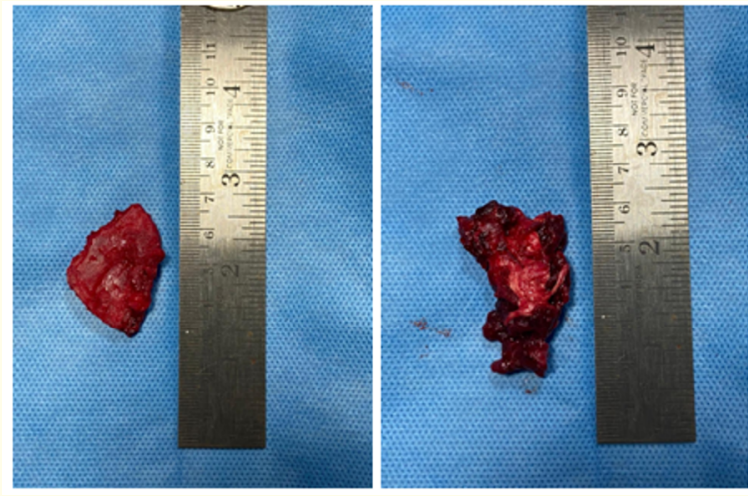

Figure 4
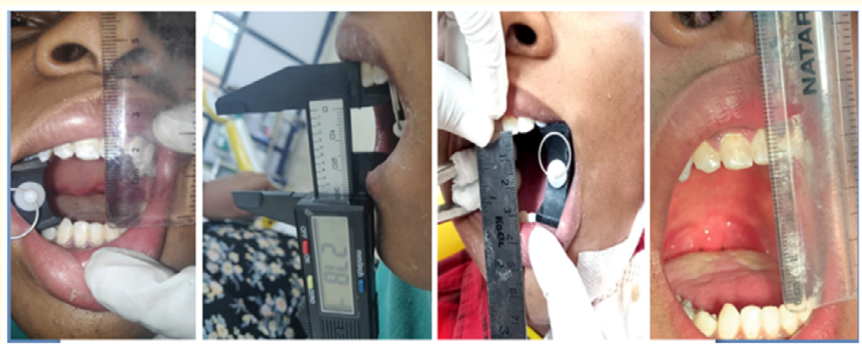

Figure 5

\section{Discussion and Conclusion}

Myositis Ossificans is the most prevalent cause of extraskeletal bone development in the major muscles of the legs, but it is unusual in the masticatory muscles, with only 52 cases reported in the English literature since 1924. The longest series of cases revealed a male predominance, with an average age of appearance ranging from 38 to 48 years $[3,4]$. In order of frequency, the masseter muscle is the most afflicted in the maxillofacial region, followed by the medial and lateral pterygoid muscles, and finally the temporalis muscle $[2,3]$.

The exterior position of the masseter, which is susceptible to direct external trauma, could be a plausible reason for this occurrence $[3,7]$. Despite the fact that trauma is thought to be the most likely cause, the actual mechanism of pathogenesis is unknown. A bone morphogenetic protein (BMP) signal from the area of injury, according to existing research, causes mesenchymal cells to differentiate into osteoblasts or chondroblasts [4].

The histology and radiological characteristics of Myositis Ossificans Traumatica have been defined as four distinct phases [8]. Proliferation of capillary and mesenchymal cells at the wound's periphery characterises the first phase. On radiographic examination, this phase is undetectable due to the lack of calcification. The incipient bone forming phase (1-2 weeks), the intermediate phase ( 4 weeks), and the late phase ( 5 weeks) all show the characteristic radiographic alterations ( 6 weeks).

The mature lesion appears as a central radiolucency surrounded by a rim of bone on radiography. 8 Excision of the MOT is best done when it is well-delineated from the surrounding skeletal muscle during the mature phase of the lesion.

MOT is distinguished by its zonal architecture, which includes peripheral ossification and a core cellular area. The outer zone is made up of active osteoclasts and mature lamellar bone. Osteoid, cartilage, or woven bone development, as well as active osteoblasts, are sometimes defined as an intermediate zone. The middle zone is frequently made up of granulation tissue-like loose fibrovascular tissue with spindle cells and conspicuous large mesenchymal cells. The most crucial feature that distinguishes MOT from osteosarcoma is its zonal architecture.

Despite the fact that the zonal phenomenon is pathognomonic for MOT, well-developed lesions might appear completely ossified with little or no indication of the cellular component.

To summarise, it is unknown why some muscles are prone to ossification while others are not. There have been no clinical or laboratory studies associated to the diagnosis. The instance also raises questions regarding the level of trauma required to start the dystrophic calcification cascade, as well as theories about how it begins. 


\section{Bibliography}

1. Cushner FD and Morwessel RM. "Myositis ossificans traumatica". Orthopedic Review 21 (1992): 1319-1326.

2. Schiff MJ and Meara DJ. "Myositis Ossificans of the Temporalis Muscle: Case Report and Review of the Literature". Journal of Oral and Maxillofacial Surgery 71 (2013): 1893-1898.

3. Boffano P., et al. "Myositis Ossificans of the Left Medial Pterygoid Muscle: Case Report and Review of the Literature of Myositis Ossificans of Masticatory Muscles". Craniomaxillofacial Trauma Reconstruction 7 (2014): 43-50.

4. Dimitroulis G. "The interpositional dermis- fat graft in the management of temporomandibular joint ankylosis". International Journal of Oral and Maxillofacial Surgery 33 (2004): 755-760.

5. Carey EJ. "Multiple bilateral parosteal bone and callus formations of the femur and left innominate bone". Archives of Surgery 8 (1924): 592-603.

6. Arima R., et al. "Traumatic myositis ossificans in the masseter muscle". Journal of Oral and Maxillofacial Surgery 42 (1984): 521-526.

7. Aoki T., et al. "Myositis Ossificans traumatina of the Masticatory Muscles: review of the literature and report of a case". Journal of Oral and Maxillofacial Surgery 60 (2002): 1083-1088.

8. Shirkhoda A., et al. "MR imaging of myositis ossificans: variable patterns at different stages". Journal of Magnetic Resonance Imaging 5 (1995): 287-292.

\section{Assets from publication with us}

- Prompt Acknowledgement after receiving the article

- Thorough Double blinded peer review

- Rapid Publication

- Issue of Publication Certificate

- High visibility of your Published work

Website: www.actascientific.com/

Submit Article: www.actascientific.com/submission.php

Email us: editor@actascientific.com

Contact us: +919182824667

Citation: Raja Sethupathy Cheeman., et al. "Myositis Ossificans of Masseter Muscle - A Rare Case Report". Acta Scientific Dental Sciences 6.2 (2022): 44-47. 